whole hospital staff, the spate of new work produced by painless surgery might make three times a week seem "almost daily." If this were the case, the total number in seven years would be just over a thousand.

"A little piece of evidence turned up," writes Dr. Sykes, "which confirmed my estimate. It shows that Syme was exaggerating when he used the vague expression "almost daily.' Mr. Annandale, who became one of Syme's successors, wrote a letter giving the exact number of operations at the Edinburgh Royal Infirmary 'for November, 1862.'

"In it he sought to indicate the wealth of material available at that institution. The figures were: Mr. Syme 13, Mr. Spence 8, Mr. Gillespie 3, Professor Miller 2 . . giving an average of just over 300 a year. This was certainly a vast-probably six-fold-increase over the figures of the pre-anaesthetic era. But it was nothing out of the ordinary, as Mr. Annandale appeared to think. Other hospitals had experienced the same increase. Thus at St. Bartholomew's 300 operations were performed in 1860.

But all these are sad, forgotten, far-off things. There are surely faults and disadvantages in over-specialization, but it is a necessity in our modern scientific world. How to meet these faults and failings is the problem of the future. But sure it is that no specialty has justified itself more than that of anaesthetics. Of that, Dr. Sykes's book will satisfy anyone, and will also provide him with plenty of good and entertaining, if somewhat discursive, reading.

Charles Singer. $\dagger$

\section{ARCHETYPAL PHYSICIAN}

A point on which all historians of medicine are at one is that medicine, as a scientific discipline, began with the Greeks. This is noteworthy in that, in the earliest Greek medical works, the number of examples in which cause and effect are manifestly related was pitifully few. Thus for the Greeks scientific medicine was rather a way of belief, a faith, even perhaps a myth. It had to contend with other myths, and not least with that of Asklepios, better known by his Latin name Aesculapius. Most of us have learned that Asklepios was originally a real being, a physician and father of two physician-sons, Podalirius and Machaon, some of whose exploits are related by Homer. Professor Kerényi seeks to show,* and has succeeded in showing, that the myth of Asklepios is far older than Homer and that we must now modify our view that Aesculapius was but a deified doctor. He believes that it entered the Greek world long before Homer, perhaps before 1500 B.C., and probably from the north, radiating from Trikka in Thessaly, Later it became widely diffused throughout the Roman world, with a centre at the metropolis and reaching even to Engand. Ultimately it attained almost the dimensions of a religion and occasionally the figure of Asklepios was even mistaken for that of Christ.

Nowadays we live in a world of specialties. Each specialism develops its own terms, almost its own language. Among such specialties is mytholography, of which Professor Kerényi is an eminent exponent. The readers of this journal would not wish us to introduce them to the technicalities of that world, so distant from that of medicine, or even from the history of medicine. It must therefore suffice here to say that Professor Kerenyi considers that in the legend of Asklepios his mother represents the dark nocturnal world of material

* Asklepios. Archetypal Image of the Physician's Existence. By C. Kerényi. (Pp. $151+x x v i i$; illustrated. 30s.) London: Thames and Hudson. 1960. birth where gather the seeds and energies for a second and more spiritual birth. The parallel to elements of Christianity is obvious. In the primordial world of mythology the vehicles of such seeds and forces frequently appear as contradictory figures, often half or wholly animal. One of these is in all our memories. $\mathrm{He}$ is Chiron, the wise and good Centaur who, according to a persistent legend, taught his art to Asklepios. But there are other semi-human beings associated with Asklepios. All these-and there are many-make the rationalism of the Hippocratic Collection even more remarkable than we thought it.

We permit ourselves one grumble. Technical terms are needed but, when not needed, are pests. This book attempts to inject into English the word mythologem. If it is to mean in English what it means in Greek, it is simply the telling or relating of a myth, and is frankly hideous and unwelcome and best forgotten. May it never enter the English dictionaries !

Charles Singer. $\dagger$

†These reviews were received shortly before Professor Singer's death on June 10 .

\section{New Appliances}

\section{MAYO'S GOITRE RETRACTOR MODIFED FOR USE AS A STERNUM SPREADER}

Mr. Kingsley Lawrance, of the Department of Thoracic Surgery, the General Infirmary at Leeds, writes: Dr. J. Kirklin, of the Mayo Clinic, first altered the Mayo goitre retractor to adapt it for satisfactory use as a sternum spreader, and in the thoracic surgical department at Leeds we have modified it still further. The instrument is made on the same principle as the Mayo retractor, but with the following modifications. (1) The maximum opening of the inner, curved portion of the blades is not less than $8 \frac{1}{2}$ in. $(21.6 \mathrm{~cm}$.). (2) When the instrument is in use the bows and shanks, including the portion up to the hinges, can be folded right over to approximately 135 degrees as compared with the 90 degrees angulation normally found on a

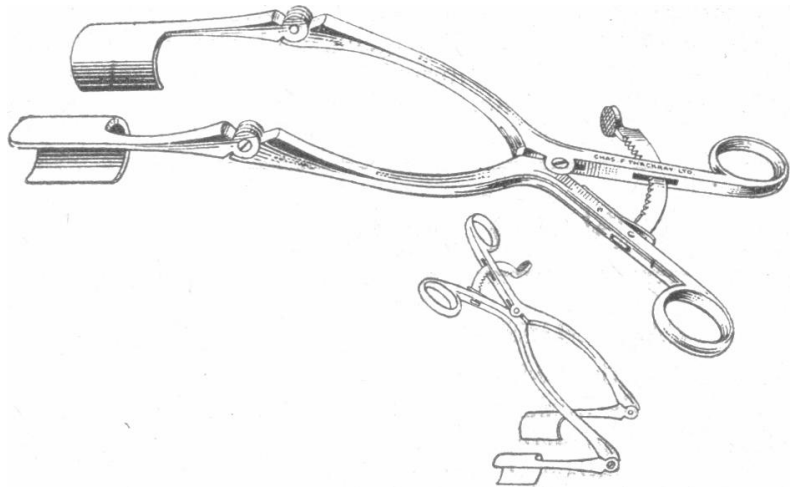

Mayo retractor modified for use as a sternum spreader.

standard Mayo retractor. The hinges are blocked to prevent angulation in the opposite direction. (3) The arms measure $4 \mathrm{in}$. $(10 \mathrm{~cm}$.) overall from the distal end of the blades to the centre of the first joint. (4) The blades are solid, being $1 \frac{1}{2}$ in. $(3.8 \mathrm{~cm}$.) wide, but of the same curvature and depth as the Mayo pattern. (5) The overall weight is approximately $50 \%$ greater than that of the standard Mayo retractor.

The resultant instrument is shown in the diagram. It was necessary to increase the various dimensions of the retractor to provide satisfactory exposure of the heart and great vessels through the midline sternal splitting incision. The 
weight of the instrument was increased so that it could be used in adults as well as children, and by making the blades solid not only is damage to tissue avoided, but sutures do not become entangled. The increase in angulation to 135 degrees permits access to the groin in small children (for femoral artery cannulation in by-pass perfusion) without removing the retractor and without danger of the handles inadvertently falling.

We have used this retractor to spread the sternum in over 30 patients who have had by-pass perfusion operations. Their ages have varied from 3 to .45 years, and the instrument has proved satisfactory for all sizes of patient. We find it a great improvement on any other retractor we have used previously for this purpose ; in addition to the points mentioned above, it is a very "discrete" retractor, in that it does not project into or invade the incision.

The retractor was made for us and can be supplied by Chas. F. Thackray, Ltd., of Leeds.

\section{A NEW FACE MASK :}

Drs. E. K. GARDNER and J. D. ROChForD, consultant anaesthetists, Barnet Group of Hospitals, write: The edentulous patient constitutes something of a problem for general anaesthesia with a mask; and we do not believe that endotracheal intubation should be an essential part of every general anaesthetic.

A search was made for a mask having the following features: (1) an outer flange to fit snugly below the mandible, (2) an internal flange to rest lightly on the anterior border of the masseter, (3) a good fit over

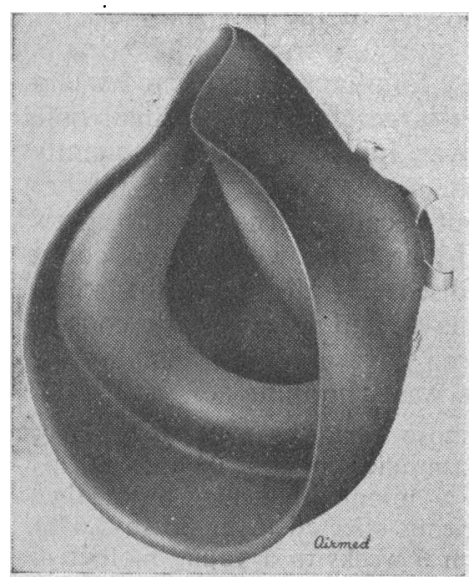

the bridge of the nose, and, preferably, (4) to provide a seal against reasonable positive and negative pressures.

Our search proved unsuccessful, and we invited Airmed to develop a new mask because we felt that their specialist knowledge of masks used in the field of anaesthesia a nd aircraft might provide the solution.

After much experimenting and testing of prototypes we have selected a mask with a fairly rigid "shell" but with soft, pliable rims and chin elevator, and having all of our original requirements. The dead space is small and the mask can be sterilized by boiling.

The mask is a one-piece moulding in antistatic rubber, known as the "duoseal," and is supplied complete with a universal harness ring and bush; the latter accommodates both the English facepiece and the American Heidbrink male fitting. The mask is available in medium size only at present, and is considered suitable for edentulous men and women, and women with teeth. Two other sizes will be available later-large for ordinary men, and small for smaller faces generally.

The duoseal may be obtained from Airmed Limited, 16, Wigmore Street, London, W.1, and at Harlow, Essex.

A first supplement, covering the 1959 literature, has been published to the annotated bibliography of the constituents of tobacco smoke. During last year a number of compounds, not previously found, have been identified in it. Perhaps the most unexpected are a number of aminoacids, sugars, and long-chain fatty-acid esters of sterols. (Tobacco Manufacturers' Standing Committee, 6-10, Bruton Street, London, W.1. Research Papers No. 3.)

\section{To-day's Drugs}

With the help of expert contributors we publish below notes on a selection of drugs in current use.

\section{Bretylium Tosylate}

"Darenthin" (Burroughs Wellcome).

This hypertensive drug has been the subject of a report in this column (February 13, page 496). A potentially serious complication of treatment with it has recently been reported in a statement issued by the manufacturers:

"It has just been reported to us that the condition of a few patients suffering from malignant hypertension and treated with 'darenthin' has seriously deteriorated between visits to the clinic. This has been attributed to the sudden and rapid development of drug tolerance. We accordingly recommend that patients at present being treated with 'darenthin' should have blood pressure readings taken at frequent intervals so that any rise in pressure may be immediately detected."

The manufacturers state that investigations are being carried out to determine whether the risk of tolerance can be reduced by simultaneous use of darenthin with chlorothiazide or a ganglion-blocking drug.

\section{Methaqualone}

" Melsedin" (Boots)

Chemistry.-Melsedin is 2-methyl-3-O-tolyl-4-quinazolone hydrochloride and has the following structural formula:

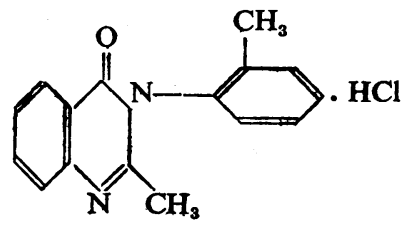

Pharmacology.-This is a recently introduced, orally active, non-barbiturate mild hypnotic.

Therapy.-In adults the hypnotic dose is usually $150 \mathrm{mg}$., but occasionally $300 \mathrm{mg}$. may be required at first in some patients. Sleep usually occurs within $\mathbf{4 0}$ minutes and lasts for six to ten hours. In children over 7 years the hypnotic dose is half the adult dose. The drug is also active when given in a suppository. In therapeutic doses there are no reports so far of a depressant action on the respiratory, cardiovascular, or haemopoietic systems, nor are there any reports of damage to liver or kidncy. Skin rashes are said not to occur. To date there is no evidence of the development of tolerance or addiction to methaqualone. The drug is excreted rapidly, therefore cumulative effects are unlikely. Hangover effects occasionally occur.

It is impossible at present to state precisely how methaqualone compares with other hypnotics, but present indications suggest that it is slightly less active and less reliable than cyclobarbitone and quinalbarbitone. The addition of $25 \mathrm{mg}$. of chlorpromazine makes it more active and more reliable as a hypnotic. The absence of reports of skin rashes with methaqualone makes it a possible alternative mild hypnotic for barbiturate-sensitive patients. There is some evidence that this drug is useful as a potentiator of the analgesic and antitussive actions of codeine and dextromethorphan.

Side-effects.-Gastric upsets have occurred in a small percentage of patients receiving this drug, while some patients are resistant even to the largest $(300 \mathrm{mg}$.) hypnotic dose, and may only become confused and giddy and develop a headache. Occasionally mild stupor has occurred on the morning after a hypnotic dose. As with barbiturates, alcohol increases the depressant effect of methaqualone on the central nervous system.

N.H.S. Basic Price. -100 150-mg. tabs., 158. 